\title{
Separation of sodium lactate from Span 80 and SDS surfactants by ultrafiltration
}

\author{
Lara Roque, Isabel Escudero*, José M. Benito \\ Department of Biotechnology and Food Science, University of Burgos, Plaza Misael \\ Bañuelos s/n, 09001 Burgos, Spain \\ E-mail addresses: Irv0010@universidaddeburgos.es (L. Roque), jmbmoreno@ubu.es \\ (J.M. Benito)
}

*Corresponding author. Tel.: +34-947258809; fax: +34-947258831. E-mail address: iescuder@ubu.es

\begin{abstract}
The ultrafiltration process for separation of sodium lactate from sorbitan monooleate (Span 80) and sodium dodecyl sulfate (SDS) surfactants using $\mathrm{ZrO}_{2}$ flat-disc ultrafiltration membranes was studied in this work. The study is focused on the influence of the nominal molecular weight limit of the membrane (NMWL), the transmembrane pressure (TMP), and initial lactic acid concentration $\left(C_{A}\right)$ on the permeate flux $\left(J_{p}\right)$ and rejections observed to ion lactate $\left(R_{A}\right)$ and SDS $\left(R_{S}\right)$ using a full central composite experimental design and response surface methodology.

Experiments were conducted in four stages: a first stage of lactic acid extraction with niosomes formulated with Span $80\left(20 \mathrm{~mol} / \mathrm{m}^{3}\right)$ and SDS $\left(4 \mathrm{~mol} / \mathrm{m}^{3}\right)$, a second backextraction stage conducted by $\mathrm{NaOH}$ addition until $\mathrm{pH}>12$ for niosomes breaking and sodium lactate releasing, and a third and fourth ultrafiltration stages at $25{ }^{\circ} \mathrm{C}$ to separate the lactate ions from the mixed surfactants.

Membrane NMWL, TMP and their interactions presented statistically significant influence on the permeate flux. Rejections to lactate ion and SDS were lower than $4.5 \%$ and higher than $86 \%$, respectively, whereas Span 80 rejection was $100 \%$ in all range of experimental conditions tested.

The optimal conditions were established for maximum values of permeate flux, and they were obtained for a 2 bar TMP and $15 \mathrm{kDa}$ NMWL membrane. Under these conditions, the rejections of SDS surfactant and lactate ion were $87.3 \%$ and $4.31 \%$, respectively, with a permeate flux of $42.63 \mathrm{~L} / \mathrm{m}^{2} \mathrm{~h}$. The antagonistic effect between permeate flux and SDS rejection is also proved.
\end{abstract}

\section{Keywords}

Lactic acid; Span 80; SDS; Ultrafiltration; Experimental design methodology

\section{Introduction}

Lactic acid is of paramount importance in pharmaceutical and food industries due to its properties as a preservative, acidulant, $\mathrm{pH}$ regulator, and flavoring. Its use has considerably increased in the last years because of the increased production of polylactic acid (PLA) biodegradable thermoplastic [1-4].

In lactic acid bioproduction, unsustainable and high energy consumption conventional separation techniques, such as precipitation with calcium hydroxide or 
solvent extraction, are usually used for the lactic acid separation from fermentation broths [5,6]. Membrane-based separation techniques [7] have proven to be effective because they can avoid accumulation of lactic acid in the fermentation broths, preventing product inhibition and increasing productivity of the fermentation process. In this way, hollow-fiber contactors using organic solvents [8-10] and micellar enhanced ultrafiltration (MEUF) using surfactants have been studied [11-14]. More recently, the use of niosomes as lactic acid extraction agents has also been studied [15].

Niosomes are vesicles formed by one or more bilayers of non-ionic surfactants enclosing an aqueous inside cavity. Niosomes are widely used in medical and pharmacological applications for their ability to microencapsulate compounds of different nature [16-20]. However, the use of niosomes as extraction agents of solutes from very low concentration aqueous solutions is a new application in the field of sustainable processes that has barely been explored.

Fraile et al. [21] observed that the addition of suitable amounts of the anionic surfactant sodium dodecyl sulfate (SDS) to non-ionic surfactant Span 80 (sorbitan monooleate) formulations yields a stabilizing effect on the niosome bilayer, improving lactic acid entrapment efficiency. However, the addition of ionic surfactants to the niosome dispersions can lead to the complete solubilization of vesicles. The solubilization process of Span 80 niosomes by addition of SDS has been recently studied [22]. It was identified as a three-stage micellization process: SDS adsorption until saturation, intensification of the bilayer solubilization by mixed micelles formation, and complete bilayer solubilization by micellization. The critical points corresponding to SDS concentration for niosome saturation and total solubilization were identified for several Span 80 niosome concentrations, being 12 and $16 \mathrm{~mol} / \mathrm{m}^{3}$ of SDS, respectively, for the $20 \mathrm{~mol} / \mathrm{m}^{3}$ Span 80 formulation.

The membrane hybrid process of lactic acid extraction by niosomes formulated with Span 80 and SDS in pre-saturation concentrations, using a $0.20 \mu \mathrm{m}$ pore size flatdisc $\mathrm{TiO}_{2}$ microfiltration membrane and 0.3 bar of transmembrane pressure, has been studied in a previous work [15]. Best results showed a 33\% lactic acid extraction degree after 30 min equilibrium time, using niosomes of Span $80\left(20 \mathrm{~mol} / \mathrm{m}^{3}\right)$ and SDS $\left(4 \mathrm{~mol} / \mathrm{m}^{3}\right)$ as extraction agents, $\mathrm{pH}<\mathrm{pKa}$ of lactic acid $(\mathrm{pKa}=3.4)$, and a SDS/lactic acid molar ratio of 0.01 . Back-extraction of lactate ion was conducted by addition of $\mathrm{NaOH}$ until $\mathrm{pH}>12$ where breaking of niosomes was observed. However, a significant permeate flux decline with respect to water flux $\left(\mathrm{J}_{\mathrm{p}} / \mathrm{J}_{\mathrm{w}}=0.38\right)$ was obtained during the separation of components due to fouling by mixed micelles and SDS monomers in the polarization layer and within the large pores of the microfiltration membrane. These results have led to the present work focused on the use of ultrafiltration (UF) membranes in order to reduce fouling and to improve the permeate flux during the back-extraction stage at $\mathrm{pH}>12$.

This work is a continuation of the previous one [15] and aims to model and optimize the removal of lactate ion from back-extraction aqueous solutions at $\mathrm{pH}>12$ containing Span 80 and SDS surfactants in the stated concentrations, using ultrafiltration membranes. A Central Composite Design (CCD) and Response Surface Methodology (RSM) were used to study the effect of the factors (lactate ion concentration, transmembrane pressure, and membrane nominal molecular weight limit), on the permeate flux and rejection of components. RSM approach was also used to gain an understanding of the concentration polarization phenomenon. The optimization of the process conditions was conducted in order to achieve maximum permeate flux and surfactants rejection, and minimum lactate ion rejection. 


\section{Materials and methods}

\subsection{Chemicals}

DL-Lactic acid (>90\% purity, Fluka) was used as solute. The non-ionic surfactant sorbitan monooleate (Span 80, >95\% purity, Sigma-Aldrich) and the anionic surfactant sodium dodecyl sulfate (SDS, 99\%, Sigma-Aldrich) were used in the formulation of niosomes. Other chemicals such as methanol (HPLC grade, HiPerSolvChromanorm), maleic acid (>99\%, Fluka), phosphoric acid (>85\%, Sigma-Aldrich), disodium hydrogen phosphate dodecahydrate (>98\%, Panreac), potassium dihydrogen phosphate (>99.5\%, Merck), sodium hydroxide (analysis grade, Scharlau), and phenolphthalein (99\%, Panreac) were used throughout the experiments. For the determination of SDS concentration the following chemicals were used: ethyl violet (99\%, Sigma-Aldrich), glacial acetic acid of analysis quality (Panreac), sodium acetate for analysis (Merck), anhydrous sodium sulfate for analysis (Scharlau), toluene (>99.5\%, AnalarNormapur VWR Chemicals) and ethylenediaminetetraacetic acid (EDTA, >99\%, Sigma-Aldrich). Ultrapure deionized Milli-Q water (Millipore, USA), with a conductivity of $0.1 \mu S / \mathrm{cm}$, was used for the preparation of all solutions.

\subsection{Niosome formation}

Niosomes were prepared by ultrasonication of $10 \mathrm{~cm}^{3}$ aqueous solutions of Span $80\left(20 \mathrm{~mol} / \mathrm{m}^{3}\right)$ and SDS $\left(4 \mathrm{~mol} / \mathrm{m}^{3}\right)$. These concentrations were chosen on the basis of previous works $[15,21]$. The application of ultrasounds was carried out over a 5-min effective time, by pulses every $5 \mathrm{~s}$ ( $5 \mathrm{~s}$ on and $5 \mathrm{~s}$ off, 60 cycles; $30 \%$ amplitude, 500 W), to avoid overheating of the sample, using a high-intensity ultrasonic processor (Vibra-Cell VCX 500, Sonics \& Materials Inc., USA) equipped with a $3 \mathrm{~mm}$-diameter titanium alloy bicylindrical probe. Following, samples were centrifuged (Eppendorf 5804 centrifuge) for $15 \mathrm{~min}$ at $9000 \mathrm{rpm}$, in order to remove any trace of metal detached from the probe.

\subsection{Experimental procedure}

UF experiments were carried out using a Spirlab filtration cell (TAMI Industries, France) with $90 \mathrm{~mm}$ diameter flat-disc ceramic membranes (INSIDE DisRAM, TAMI Industries, France), made of a $\mathrm{ZrO}_{2}$ active layer supported on $\mathrm{TiO}_{2}$, with $56.3 \mathrm{~cm}^{2}$ of effective area. The nominal molecular weight limits (NMWL) of the membranes were 3 , 8 and $15 \mathrm{kDa}$.

All experiments were conducted using the following four-stage protocol:

1. Extraction stage: it was carried out by mixing $400 \mathrm{~cm}^{3}$ of aqueous solution containing lactic acid $\left(C_{A}=5,10\right.$ and $\left.15 \mathrm{~mol} / \mathrm{m}^{3}\right)$, named as $F_{0}$, and $10 \mathrm{~cm}^{3}$ of dispersed phase containing niosomes, named as $F_{d}$. The mixture was continuously stirred at $375 \mathrm{rpm}$ and $20^{\circ} \mathrm{C}$ for $30 \mathrm{~min}$ to reach equilibrium.

2. Back-extraction stage: this stage was performed by addition of a required volume of $\mathrm{NaOH}(1 \mathrm{~N})$ aqueous solution to the above mentioned dispersion until $\mathrm{pH}$ about $12.2 \pm 0.2$. It was allowed $45-50 \mathrm{~min}$ to reach equilibrium and then a $60 \mathrm{~cm}^{3}$ sample was withdrawn for analysis. The sample and remaining dispersion were identified as $\mathrm{F}_{\text {bis. }}$.

3. UF stage in constant concentration mode. The feed solution $\left(F_{b i s}\right)$ was fed to the ultrafiltration cell by a peristaltic pump (Masterflex I/s economy drive Cole Parmer, CRS rotor EW-07518-00) at a prefixed flow rate and pressure. Permeate and retentate streams were recirculated to the $1 \mathrm{~L}$ jacketed feed tank, 
where the feed solution was kept at constant temperature $\left(20^{\circ} \mathrm{C}\right)$ and stirred at $375 \mathrm{rpm}$. Adjustment of transmembrane pressure (TMP) was achieved by a needle valve located in the retentate stream. The system is also equipped with a flowmeter and a pressure gauge, both placed at the inlet of the filtration cell. Experiments were run for 30 min under specific TMP (1, 1.5 or 2 bar) in order to achieve stable conditions in the polarization layer and membrane. Subsequently, a $60 \mathrm{~cm}^{3}$ sample was withdrawn for analysis and the sample and remaining dispersion were identified as $\mathrm{F}$.

4. UF stage in concentration mode. Once the equilibrium with the membrane was reached, the feed solution $F$ was ultrafiltrated in concentration mode, removing continuously the permeate stream and recirculating the retentate to the feed tank up to a volume concentration ratio (VCR, the quotient between initial feed volume and retentate volume) around 2 . The permeate flux was calculated by measuring the time needed for collecting $10 \mathrm{~cm}^{3}$ permeate samples. Finally, permeate and retentate were separated for analysis and named as $\mathrm{P}$ and $\mathrm{R}$, respectively.

Fig. 1 shows a scheme of the four-stage procedure and the set-up of the UF experimental equipment. Table 1 summarizes the analytical measurements made to different samples through the experimental process.

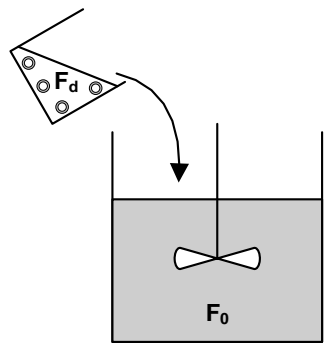

EXTRACTION STAGE
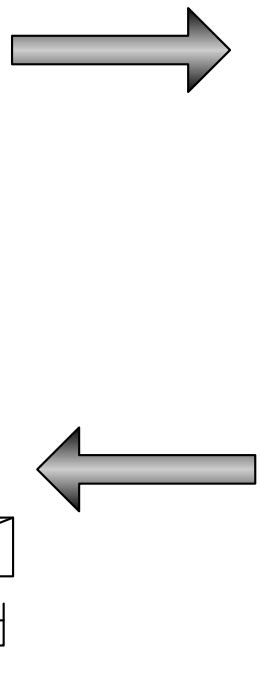

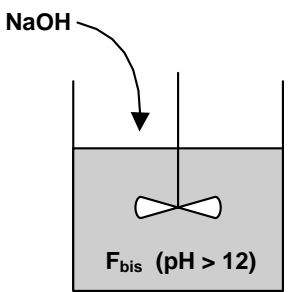

BACK-EXTRACTION STAGE

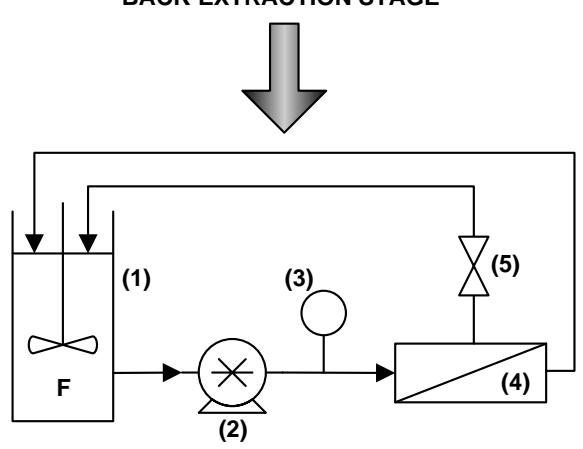

CONSTANT CONCENTRATION MODE UF STAGE

Figure 1. Schematic diagram of the four-stage experimental procedure. $F_{d}$ : dispersed phase, $\mathrm{F}_{\mathrm{o}}$ : continuous phase, $\mathrm{F}_{\text {bis }}$ : dispersion at $\mathrm{pH}>12$ without membrane contact, $\mathrm{F}$ : feed dispersion at $\mathrm{pH}>12$ in contact with the membrane under UF conditions at constant concentration, $\mathrm{P}$ and R: permeate and retentate after UF in concentration mode, 1: feed tank, 2: peristaltic pump, 3: pressure gauge, 4: membrane module, 5: needle valve.

Membrane cleaning was accomplished afterwards by rinsing with deionized water to remove the foam, followed by washing with $0.1 \mathrm{~N}$ sodium hydroxide solution for 30 min, and then with $0.17 \mathrm{wt} \%$ phosphoric acid solution for $30 \mathrm{~min}$. A final rinsing step with deionized water until neutrality was sufficient to restore the initial water flux of the membrane. 
Table 1. Summary of analytical measurements made to samples through the experimental procedure.

\begin{tabular}{|c|c|c|}
\hline Sample & Description & Analytical measurements \\
\hline $\mathrm{F}_{\mathrm{o}}$ & $\begin{array}{l}\text { Lactic acid aqueous solution (initial } \\
\text { continuous phase) }\end{array}$ & Lactic acid concentration and $\mathrm{pH}$ \\
\hline$F_{d}$ & $\begin{array}{c}\text { Aqueous dispersion of niosomes (initial } \\
\text { dispersed phase) }\end{array}$ & Size, PDI, zeta potential, and pH \\
\hline $\mathrm{F}_{\mathrm{bis}}$ & $\begin{array}{c}\text { Equilibrium dispersion at } \mathrm{pH}>12 \text { (without } \\
\text { membrane) }\end{array}$ & $\begin{array}{c}\text { Lactate ion concentration, SDS } \\
\text { monomers concentration, size, PDI, } \\
\text { zeta potential, and pH }\end{array}$ \\
\hline $\mathrm{F}$ & $\begin{array}{l}\text { Bulk dispersion at } \mathrm{pH}>12 \text { under steady- } \\
\text { state UF conditions in constant } \\
\text { concentration mode }\end{array}$ & $\begin{array}{l}\text { Lactate ion concentration, SDS } \\
\text { monomers concentration, size, PDI, } \\
\text { zeta potential, and pH }\end{array}$ \\
\hline $\mathrm{P}$ & $\begin{array}{l}\text { Final permeate after UF in concentration } \\
\text { mode }(\mathrm{VCR}=2)\end{array}$ & $\begin{array}{l}\text { Lactate ion concentration, SDS } \\
\text { monomers concentration, size, PDI, } \\
\text { zeta potential, and pH }\end{array}$ \\
\hline $\mathrm{R}$ & $\begin{array}{l}\text { Final retentate after UF in concentration } \\
\text { mode }(\mathrm{VCR}=2)\end{array}$ & $\begin{array}{c}\text { Lactate ion concentration, SDS } \\
\text { monomers concentration, size, PDI, } \\
\text { zeta potential, and pH }\end{array}$ \\
\hline
\end{tabular}

\subsection{Analytical methods}

Lactate ion concentration was determined by high performance liquid chromatography using a HPLC Shimadzu. A reverse phase column ACE 5C18 (ACE HPLC columns) and a UV-vis detector at $216 \mathrm{~nm}$ were used. Detailed conditions of the analytical method can be found elsewhere [15]. Samples were measured in triplicate and the analytical error was lower than $\pm 0.001 \mathrm{~mol} / \mathrm{m}^{3}$.

SDS monomer concentration was determined by spectrophotometry at $615 \mathrm{~nm}$ with a Hitachi U-2000 equipment, using the ethyl violet method [23]. Samples were measured in triplicate and the analytical error was lower than $\pm 0.002 \mathrm{~mol} / \mathrm{m}^{3}$.

The particle size distribution, the mean hydrodynamic diameter and the polydispersity index (PDI) of the samples were carried out by dynamic light scattering (DLS) using a Zetasizer Nano ZS apparatus (Malvern Instruments Ltd., UK). The PDI is a dimensionless measure of the width of the size distribution ranging from 0 to 1 , a higher value being indicative of a broader distribution of particle size. The average value and the relative error of the 3 replicates, each of 5 measurements at $20{ }^{\circ} \mathrm{C}$, was considered for each sample.

Zeta potential measurements were conducted with the aforementioned Zetasizer Nano ZS apparatus, using the Laser Doppler Velocimetry technique. They were performed on the same sample previously prepared to measure the particle size, but using the appropriate DTS1061 disposable folded capillary cell equipped with electrodes to allow the passage of electric current and the movement of the particles according to their charge [24]. Six replicates of 11 measurements were performed for each sample at $20^{\circ} \mathrm{C}$.

The $\mathrm{pH}$ measurement was performed at $20{ }^{\circ} \mathrm{C}$ using a Crison GLP $22 \mathrm{pH}$-meter fitted with a Crison 52-02 glass pH electrode (Crison, Spain), with an error of $\pm 0.01 \mathrm{pH}$ units. 
Morphological analysis of niosomes was performed by negative staining transmission electron microscopy (NS-TEM), using a JEOL-2000 EX-II TEM operating at $160-180 \mathrm{kV}$, with an image resolution of $1 \mathrm{~nm}$, located at the University of Oviedo (Spain). A droplet of the selected sample was placed on a carbon-coated copper grid, and the sample excess was removed using a piece of filter paper. Then, a drop of phosphotungstic acid solution ( $2 \% \mathrm{w} / \mathrm{v})$ was applied to the carbon grid and left for 2 min. Once the excess of staining agent was removed by absorbing with the filter paper, the sample was air-dried and the thin film of stained niosomes was observed by TEM.

\subsection{Experimental design and statistical analysis}

Response Surface Methodology (RSM) and Central Composite Design (CCD) with three levels of each independent variable were used to study the effect of NMWL $\left(\mathrm{X}_{1}\right.$ : 3-15 kDa), TMP $\left(X_{2}: 1-2\right.$ bar) and lactic acid initial concentration $\left(X_{3}: 5-15 \mathrm{~mol} / \mathrm{m}^{3}\right)$ on the permeate flux $\left(J_{p}\right)$, lactate ion observable rejection $\left(R_{A}\right)$, and SDS observable rejection $\left(R_{S}\right)$. The factors and levels studied are summarized in Table 2. Based on the selected high and low levels, the NMWL ideal central point should be $9 \mathrm{kDa}$. However, a $8 \mathrm{kDa}$ membrane was used at the central points in this study, assuming that this change does not significantly influence the experimental design.

Table 2. Factors and levels studied.

\begin{tabular}{lccc}
\hline \multirow{2}{*}{\multicolumn{1}{c}{ Factors }} & \multicolumn{3}{c}{ Levels } \\
\cline { 2 - 4 } & Low $(-1)$ & Centre $(0)$ & High $(+1)$ \\
\hline $\mathrm{X}_{1}: \mathrm{NMWL}(\mathrm{kDa})$ & 3 & 8 & 15 \\
$\mathrm{X}_{2}: \mathrm{TMP}(\mathrm{bar})$ & 1 & 1.5 & 2 \\
$\mathrm{X}_{3}: \mathrm{C}_{\mathrm{A}}\left(\mathrm{mol} / \mathrm{m}^{3}\right)$ & 5 & 10 & 15 \\
\hline
\end{tabular}

The response variables were calculated using the following equations:

$$
\begin{aligned}
& J_{p}=\frac{V}{t \times A} \\
& R_{i}=1-\frac{C_{i(p)}}{C_{i(F b i s)}}
\end{aligned}
$$

where $\mathrm{V}$ is the volume of the permeate sample collected, $\mathrm{t}$ is the time needed for collecting the permeate sample, $A$ is the membrane effective area $\left(56.3 \mathrm{~cm}^{2}\right)$, and $C_{i(p)}$ and $\mathrm{C}_{\mathrm{i}(\mathrm{Fbis})}$ are the total concentration of lactate ion or SDS in the final permeate and dispersion at $\mathrm{pH}>12\left(\mathrm{~F}_{\mathrm{bis}}\right.$ dispersion), respectively.

The CCD model generated 17 experimental runs with three replicates at the central point which highlight the reproducibility of the experiments. A second-order degree polynomial equation was used to express each predicted response $(Y)$ as a function of the independent variables under study $\left(X_{1}, X_{2}\right.$ and $\left.X_{3}\right)$. The model equation is as follows:

$$
Y=a_{0}+a_{1} X_{1}+a_{2} X_{2}+a_{3} X_{3}+a_{11} x_{1}^{2}+a_{22} X_{2}^{2}+a_{33} X_{3}^{2}+a_{12} X_{1} x_{2}+a_{13} x_{1} X_{3}+a_{23} x_{2} X_{3}
$$


where $Y$ represents the response variable $\left(J_{p}, R_{A}\right.$, and $R_{S}$, in this case $), a_{0}$ is a constant, and $a_{i}, a_{i i}, a_{i j}$ are the linear, quadratic, and interactive coefficients, respectively. Analysis of variance (ANOVA) and least significant difference (LSD) test were applied to detect the effect of the factors and statistically significant differences among values, respectively. The model was fitted by multiple linear regressions (MLR). The validity of the empirical model was tested with ANOVA. The significance of each estimated regression coefficient was assessed through values of the statistic parameters $\mathrm{F}$ and $\mathrm{p}$ (probability) with a 95\% confidence level. The experimental design and data analysis were performed using STATGRAPHICS Centurion XVI (Statpoint Technologies, Inc., Warrenton, VA, USA).

Optimal conditions were determined with the help of the STATGRAPHICS Centurion XVI software, in order to reach the maximum permeate flux and SDS rejection, and the minimum lactate ion rejection, according with the work objectives.

\section{Results and discussion}

\subsection{Effect of $\mathrm{NaOH}$ addition on the breakup of niosomes}

Particle size measurement in the dispersed phase $\left(F_{d}\right)$ reveals niosomes of 200 $\mathrm{nm}$ average diameter and a PDI value of 0.27 , which indicates a homogeneous population (Fig. 2a). Otherwise, detailed analysis of DLS intensity data of dispersions at $\mathrm{pH}>12$ revealed that the main peak observed in $\mathrm{F}_{\mathrm{d}}$, which is attributed to niosomes, disappears in these samples indicating niosome destruction by the addition of $\mathrm{NaOH}$ until $\mathrm{pH}>12$. However, peaks associated with mixed micelles of 78-80 nm in size and Span 80 aggregates larger than $1000 \mathrm{~nm}$ were observed in any of the $F_{b i s}, F$ and $R$ dispersions. Results corresponding to a $\mathrm{R}$ dispersion are also depicted in Fig. 2a. They are according with previous works $[15,21]$. As expected, zeta potential values between -45 and $-38.5 \mathrm{mV}$ were obtained in the $F_{d}$ samples used in different experiments ($40.8 \mathrm{mV}$ for $F_{d}$ sample shown in Fig. $2 b$ ), which indicate the presence of negatively charged niosomes due to the SDS adsorbed in their surface. Besides, as shown in Fig. $2 \mathrm{~b}$, two particle populations are observed in the $\mathrm{R}$ dispersion, with zeta potential values of -8 and $-20 \mathrm{mV}$, indicating weakly negatively charged particles. Similar results were obtained for any of $F_{\text {bis }}$ and $F$ dispersions (not shown), which corroborate the breakup of the niosomes at $\mathrm{pH}>12$. No particles were found in permeates, regardless of the membrane NMWL.

The presence and morphology of niosomes in the dispersed phase $\left(F_{d}\right)$ have been confirmed by TEM measurements. Fig. 3 shows two photomicrographs of formulations of $20 \mathrm{~mol} / \mathrm{m}^{3}$ of Span 80 and $4 \mathrm{~mol} / \mathrm{m}^{3}$ of SDS, where the white areas correspond to the grid. Fig. 3a shows the presence of spherical niosomes of about $200 \mathrm{~nm}$ in $F_{d}$, whose sizes agree with those measured by DLS. Fig. 3b shows absence of niosomes in the dispersion at $\mathrm{pH}>12\left(\mathrm{~F}_{\mathrm{bis}}\right)$. Fig. $3 \mathrm{~b}$ could correspond to large structures of Span 80, as its concentration $\left(20 \mathrm{~mol} / \mathrm{m}^{3}\right)$ is well above its $\mathrm{CMC}\left(\approx 0.1 \mathrm{~mol} / \mathrm{m}^{3}\right.$ in water [25]), and they would be in accordance with the large particles shown in Fig. $2 a$. 


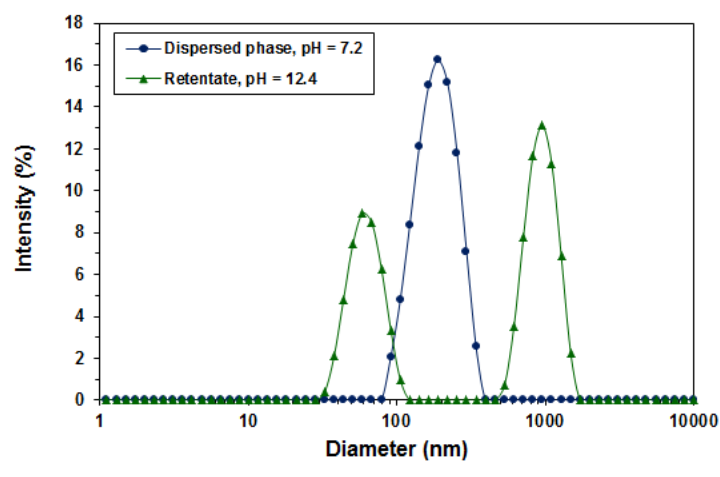

(a)

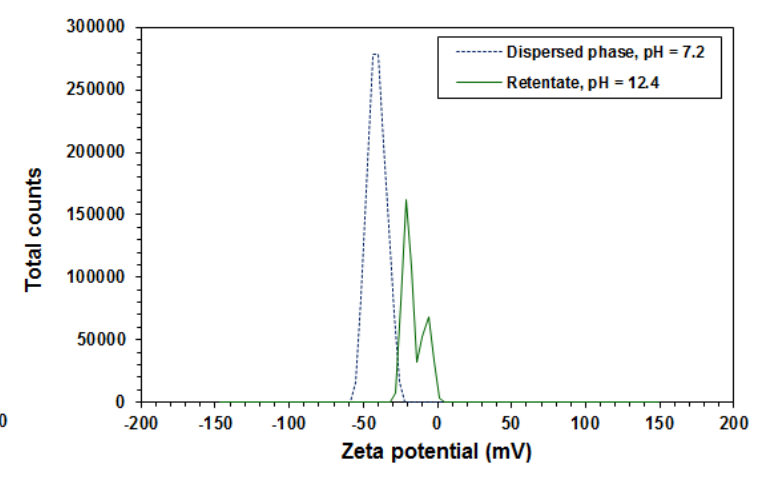

(b)

Figure 2. (a) Particle size distributions corresponding to dispersed phase, $F_{d}$, and retentate, $R$, and (b) Zeta potential of $F_{d}$ and $R$ dispersions, as described in Table 1.

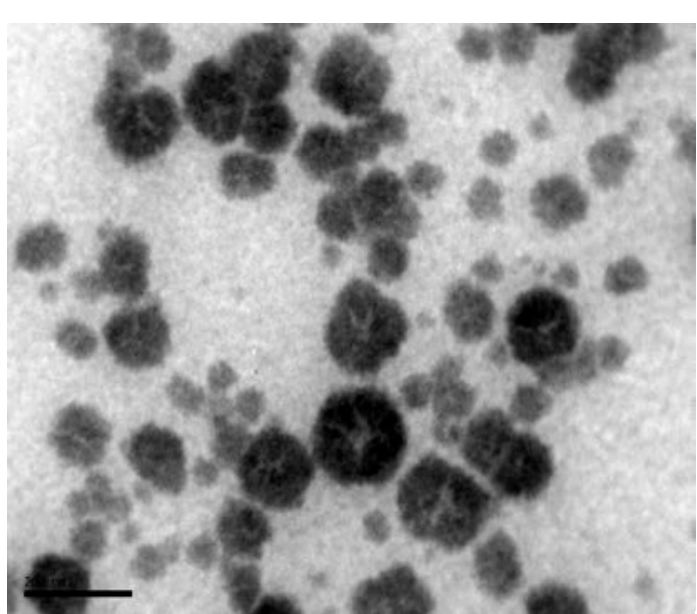

(a)

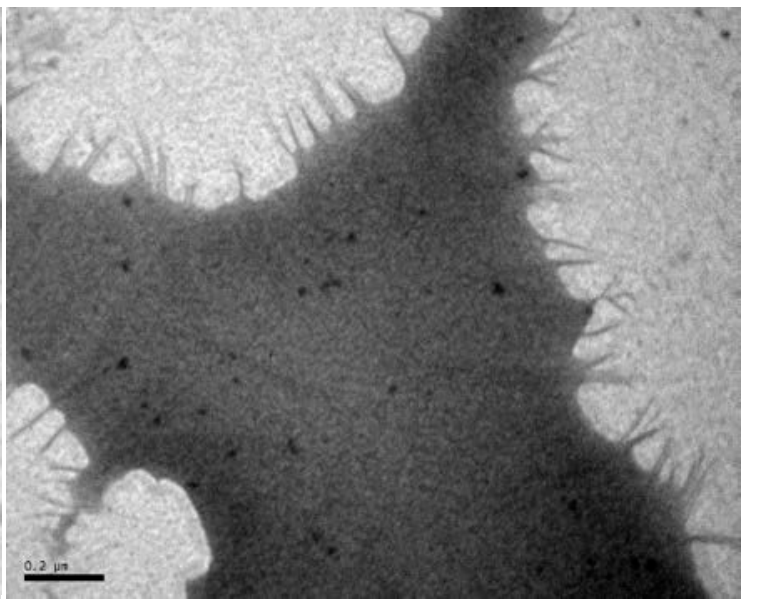

(b)

Figure 3. TEM micrographs. (a) Niosomes of Span $80\left(20 \mathrm{~mol} / \mathrm{m}^{3}\right)$ and SDS $\left(4 \mathrm{~mol} / \mathrm{m}^{3}\right)$ in the dispersed phase $\left(F_{d}\right)$. (b) Formulation of Span $80\left(20 \mathrm{~mol} / \mathrm{m}^{3}\right)$ and SDS $\left(4 \mathrm{~mol} / \mathrm{m}^{3}\right)$ in aqueous solution at $\mathrm{pH}>12\left(\mathrm{~F}_{\mathrm{bis}}\right)$. Scale bars: $0.2 \mu \mathrm{m}$.

It is well documented that addition of low concentration of cations to anionic surfactant (SDS) solutions decreases the repulsive forces between head groups of SDS monomers due to the electrostatic shielding effect, resulting in the formation of micelles at lower concentration than its $\operatorname{CMC}\left(8.1 \mathrm{~mol} / \mathrm{m}^{3}\right.$ in water $\left.[11,26-32]\right)$. However, beyond a critical concentration, the sodium ions start disrupting the micellar packing, resulting in less stable micelles $[29,30]$.

In light of the results, it can be assumed that the presence of Span 80 monomers is highly improbable in dispersions at $\mathrm{pH}>12$ due to its hydrophobic character (HLB = 4.3 [20]), whereas the coexistence of large Span 80 aggregates with mixed micelles and SDS surfactant monomers is highly probably. 


\subsection{Experimental design}

The matrix of the CCD and experimental values of the response variables are given in Table 3.

Table 3. Matrix of the central composite design (CCD) and experimental values of the response variables: permeate flux $\left(\mathrm{J}_{\mathrm{p}}\right)$, lactate ion observable rejection $\left(\mathrm{R}_{\mathrm{A}}\right)$, and SDS observable rejection $\left(R_{S}\right)$.

\begin{tabular}{|c|c|c|c|c|c|c|}
\hline \multirow[b]{2}{*}{ Experiment } & \multicolumn{3}{|c|}{ Factors } & \multicolumn{3}{|c|}{ Responses } \\
\hline & $\begin{array}{l}\text { NMWL } \\
\text { (kDa) }\end{array}$ & $\begin{array}{l}\begin{array}{l}\text { TMP } \\
\text { (bar) }\end{array} \\
\end{array}$ & $\begin{array}{c}\mathrm{C}_{\mathrm{A}} \\
\left(\mathrm{mol} / \mathrm{m}^{3}\right)\end{array}$ & $\begin{array}{c}J_{p} \\
\left(L / m^{2} h\right)\end{array}$ & $\mathbf{R}_{\mathbf{A}}$ & $\mathbf{R}_{\mathbf{S}}$ \\
\hline 1 & 15 & 1 & 5 & $15,99^{\mathrm{abc}}$ & $0.0191^{\mathrm{a}}$ & $0,897^{a}$ \\
\hline 2 & 8 & 1,5 & 10 & $24,51^{c d}$ & $0.0182^{a}$ & $0,864^{a}$ \\
\hline 3 & 3 & 1 & 15 & $8,53^{a}$ & $0.0115^{a}$ & $0,888^{a}$ \\
\hline 4 & 8 & 1,5 & 5 & $26,64^{\mathrm{cd}}$ & $0.0160^{a}$ & $0,865^{a}$ \\
\hline 5 & 3 & 1,5 & 10 & $12,79^{\mathrm{ab}}$ & $0.0056^{a}$ & $0,881^{a}$ \\
\hline 6 & 15 & 1,5 & 10 & $34,10^{\text {de }}$ & $0.0315^{a}$ & $0,880^{a}$ \\
\hline 7 & 8 & 1,5 & 15 & $19,18^{\mathrm{cd}}$ & $0.0171^{a}$ & $0,891^{a}$ \\
\hline 8 & 8 & 1 & 10 & $14,92^{\mathrm{abc}}$ & $0.0117^{\mathrm{a}}$ & $0,881^{a}$ \\
\hline 9 & 8 & 1,5 & 10 & $22,38^{\mathrm{cd}}$ & $0.0208^{a}$ & $0,866^{a}$ \\
\hline 10 & 15 & 1 & 15 & $17,05^{\mathrm{abcd}}$ & $0.0193^{a}$ & $0,887^{a}$ \\
\hline 11 & 3 & 1 & 5 & $9,06^{a}$ & $0.0025^{a}$ & $0,902^{a}$ \\
\hline 12 & 3 & 2 & 5 & $20,25^{\mathrm{bcd}}$ & $0.0313^{a}$ & $0,889^{a}$ \\
\hline 13 & 15 & 2 & 5 & $42,63^{f}$ & $0.0431^{a}$ & $0,873^{a}$ \\
\hline 14 & 15 & 2 & 15 & $40,50^{\dagger}$ & $0.0448^{a}$ & $0,870^{a}$ \\
\hline 15 & 8 & 1,5 & 10 & $23,45^{\mathrm{cd}}$ & $0.0077^{a}$ & $0,871^{a}$ \\
\hline 16 & 8 & 2 & 10 & $27,71^{\text {de }}$ & $0.0055^{a}$ & $0,869^{a}$ \\
\hline 17 & 3 & 2 & 15 & $17,05^{\mathrm{abcd}}$ & $0.0313^{a}$ & $0,890^{a}$ \\
\hline
\end{tabular}

Table 3 shows that $J_{p}$ values present large variation, between 8 and $43 \mathrm{~L} / \mathrm{m}^{2} h$. However, $R_{A}$ and $R_{S}$ values were lower than $4.5 \%$ and higher than $86 \%$, respectively, with very similar values among them for all experiments. LSD test was applied for each response variable, revealing that $R_{A}$ and $R_{S}$ values were no significantly different $(p>$ 0.05 ). However, $J_{p}$ values identified in Table 3 that do not share a same letter were considered statistically different among them $(p<0.05)$.

ANOVA of the fitted model for the $J_{p}$ response shows that the model was statistically significant $(p$-value $=0.001)$. Table 4 shows that NMWL, TMP and their interaction are statistically significant $(p<0.05)$ on $J_{p}$. $F$ values indicate that, for the range of factors studied, NMWL and TMP factors have the stronger influence on $J_{p}$, and also that interaction between NMWL and TMP has synergistic effect on $\mathrm{J}_{\mathrm{p}}$. Otherwise, $C_{A}$ factor was not significant on $\mathrm{J}_{\mathrm{p}}$, indicating that it does not contribute on the $J_{p}$ response, in the range of concentrations tested. 
Table 4. Analysis of variance (ANOVA) for the model. Response: permeate flux $\left(\mathrm{J}_{\mathrm{p}}\right)$.

\begin{tabular}{lccccc}
\hline \multicolumn{1}{c}{ Factors } & SS & DF & MS & F-value & p-value \\
\hline $\mathrm{X}_{1}: \mathrm{NMWL}$ & 682.111 & 1 & 682.111 & 131.17 & 0.0017 \\
$\mathrm{X}_{2}: \mathrm{TMP}$ & 702.524 & 1 & 702.524 & 135.09 & 0.0016 \\
$\mathrm{X}_{3}: \mathrm{C}_{\mathrm{A}}$ & 14.6575 & 1 & 14.6575 & 2.82 & 0.0694 \\
$\mathrm{X}^{2}{ }_{1}$ & 3.45166 & 1 & 3.45166 & 0.66 & 0.2232 \\
$\mathrm{X}_{1} \mathrm{X}_{2}$ & 119.472 & 1 & 119.472 & 22.97 & 0.0094 \\
$\mathrm{X}_{1} \mathrm{X}_{3}$ & 1.51815 & 1 & 1.51815 & 0.29 & 0.3668 \\
$\mathrm{X}^{2}{ }_{2}$ & 9.59837 & 1 & 9.59837 & 1.85 & 0.1006 \\
$\mathrm{X}_{2} \mathrm{X}_{3}$ & 4.29245 & 1 & 4.29245 & 0.83 & 0.1911 \\
$\mathrm{X}^{2}{ }_{3}$ & 0.237523 & 1 & 0.237523 & 0.05 & 0.6921 \\
Lack of fit & 34.1339 & 5 & 6.82679 & 6.02 & 0.1486 \\
Pure error & 2.26847 & 2 & 1.13423 & & \\
\hline \multicolumn{5}{c}{ SS (sum of squares), DF (degrees of freedom), MS (mean of squares) }
\end{tabular}

Considering the significance of the factors, expressed by $p$-values, the empirical model was simplified, and experimental data were fitted to Eq. 4, which was able to correctly predict the permeate flux. Fig. 4 depicts the closeness between the observed and predicted values of the permeate flux.

$$
J_{p}=-17.0207-0.109287 * N M W L+30.8566 * T M P+1.28459 * N M W L * T M P
$$

The model obtained (Eq. 4) was robust and showed no lack of fit ( $p>0.05$, Table $4)$, with high value of the coefficient of determination $\left(R^{2}=0.942\right)$, high adjusted statistical coefficient $\left(R^{2}\right.$ adj $\left.=0.923\right)$ and a normal distribution of the residuals.

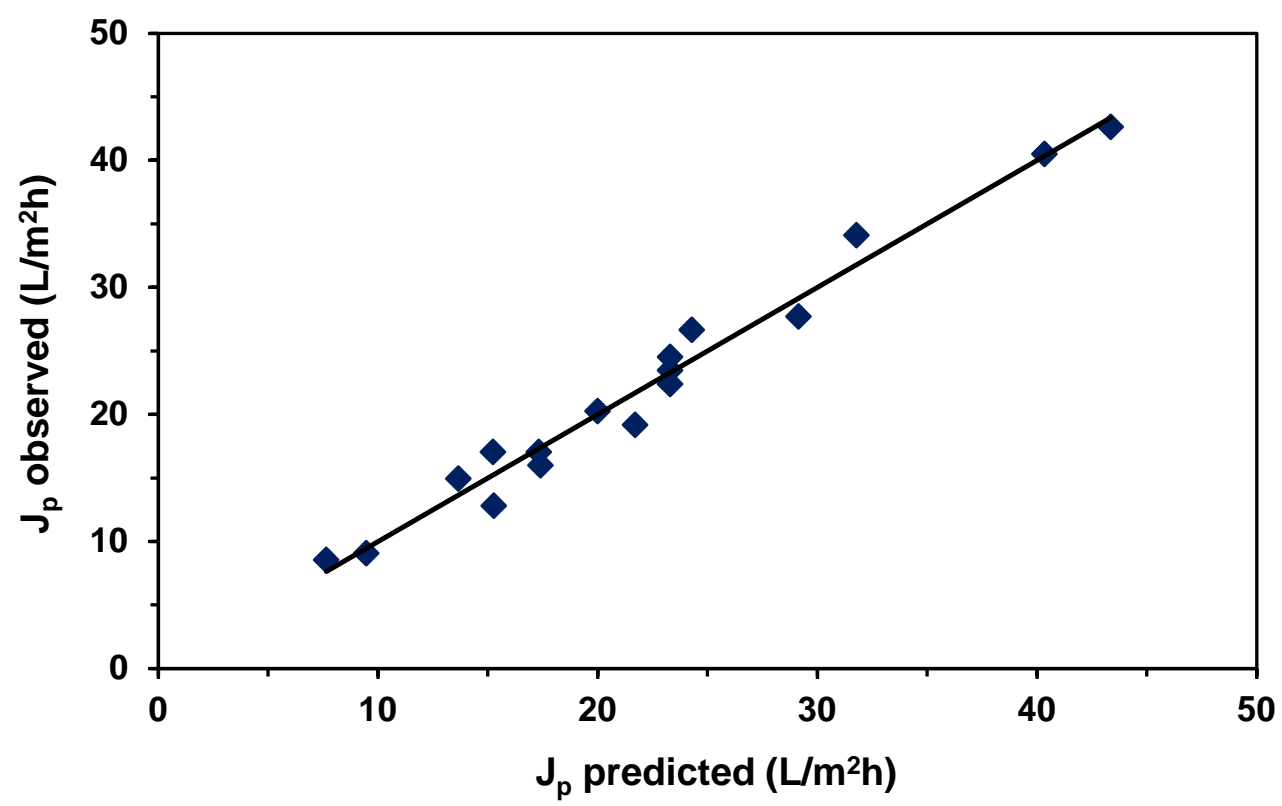

Figure 4. Observed vs. predicted values for permeate flux. 
In order to study the effect of the independent variables on $J_{p}$, surface response and contour plots of the model were generated by varying two of the independent variables within the experimental range while holding the third one constant at the central point. Fig. 5 shows that NMWL and TMP factors, and their interaction, have a statistically significant positive effect on the permeate flux. A TMP increase causes a positive effect on $J_{p}$ increase, being more appreciable as NMWL increases. This behavior can also be seen later in Fig. 6 .
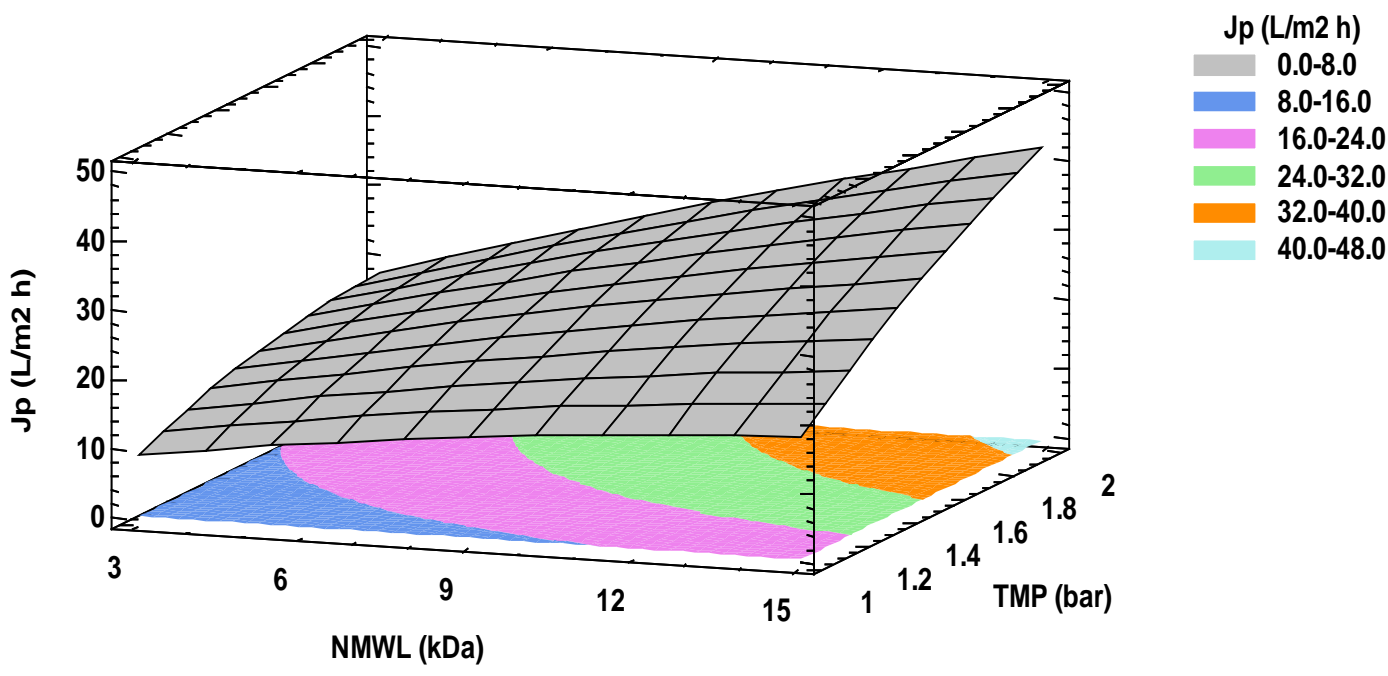

Figure 5. Response surface and contour plots of $J_{p} v s$. NMWL and TMP for $C_{A}=10 \mathrm{~mol} / \mathrm{m}^{3}$.

\subsection{Optimization of operating conditions}

Optimal conditions were established by maximizing the permeate flux. Rejections of lactate ion and SDS were not optimized because they are no statistically different between them (LSD test, $p>0.05$ ), in the range of concentrations tested. Table 5 shows that best results can be obtained using the $15 \mathrm{kDa}$ NMWL ultrafiltration membrane, and 2 bar TMP. Under these conditions, corresponding to experiment 13 of Table 3, predicted values of $J_{p}, R_{S}$, and $R_{A}$ were $43.35 \mathrm{~L} / \mathrm{m}^{2} h, 87.05 \%$, and $1.6 \%$, respectively.

Table 5. Optimal operating conditions for the ultrafiltration process, and predicted and experimental values of the response variables $J_{p}, R_{A}$, and $R_{S}$.

\begin{tabular}{ccccccc}
\hline Response & Optimization & Prediction & $\begin{array}{c}\text { Lower limit } \\
\mathbf{( 9 5 . 0 \% )}\end{array}$ & $\begin{array}{c}\text { Upper limit } \\
\mathbf{( 9 5 . 0 \% )}\end{array}$ & Factor & $\begin{array}{c}\text { Optimal } \\
\text { conditions }\end{array}$ \\
\hline $\mathrm{J}_{\mathrm{p}}$ & yes & 43.3483 & 38.5473 & 48.1493 & $\mathrm{NMWL}$ & 15.0 \\
$\mathrm{R}_{\mathrm{A}}$ & & 0.0159915 & -0.0134268 & 0.0454098 & $\mathrm{TMP}$ & 2.0 \\
$\mathrm{R}_{\mathrm{S}}$ & & 0.870568 & 0.852023 & 0.889112 & $\mathrm{C}_{\mathrm{A}}$ & 5.0 \\
\hline
\end{tabular}

\subsection{Relationship between permeate flux and SDS rejection}

Fig. 6 shows that $\mathrm{J}_{\mathrm{p}}$ linearly increases with TMP, a fact that is more significant for the $15 \mathrm{kDa}$ membrane. Similar results were obtained in several works [31-33]. The linear behavior of $\mathrm{J}_{\mathrm{p}}$ with TMP shown in Fig. 6 means that the process is mainly 
controlled by convection; however, accumulation of species near the membrane takes place and concentration polarization layer contributes, to some extent, as a resistance to permeation. Variation of $J_{\mathrm{p}}$ with TMP during the concentration process for the $15 \mathrm{kDa}$ membrane is depicted in Fig. 7: $\mathrm{J}_{\mathrm{p}}$ was kept constant during the concentration process by ultrafiltration, indicating stable conditions of the membrane surface and polarization layer during this stage.

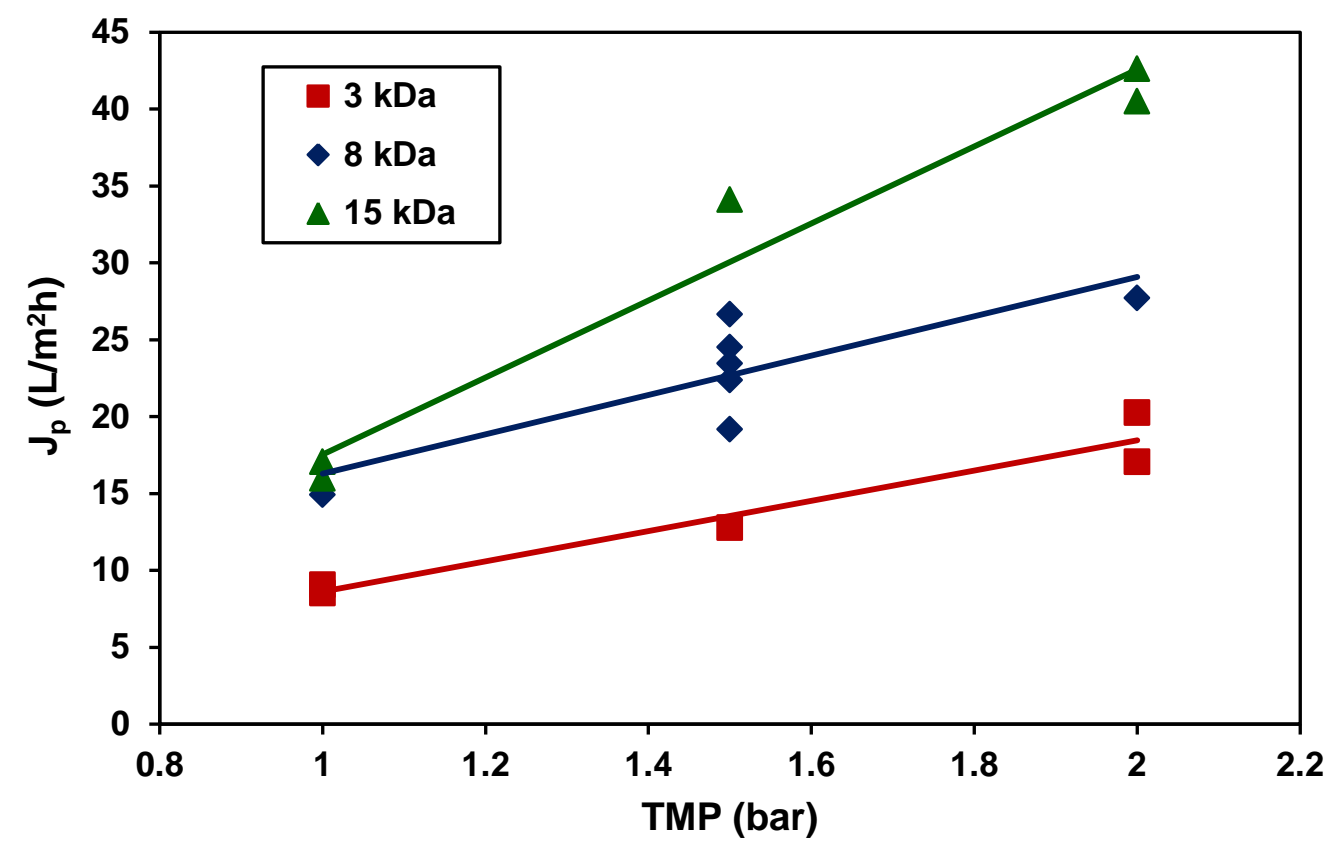

Figure 6. Permeate flux variation with TMP using different NMWL ceramic membranes $(3,8$ and $15 \mathrm{kDa}$ ). Symbols: experimental data. Lines: behavior trends.

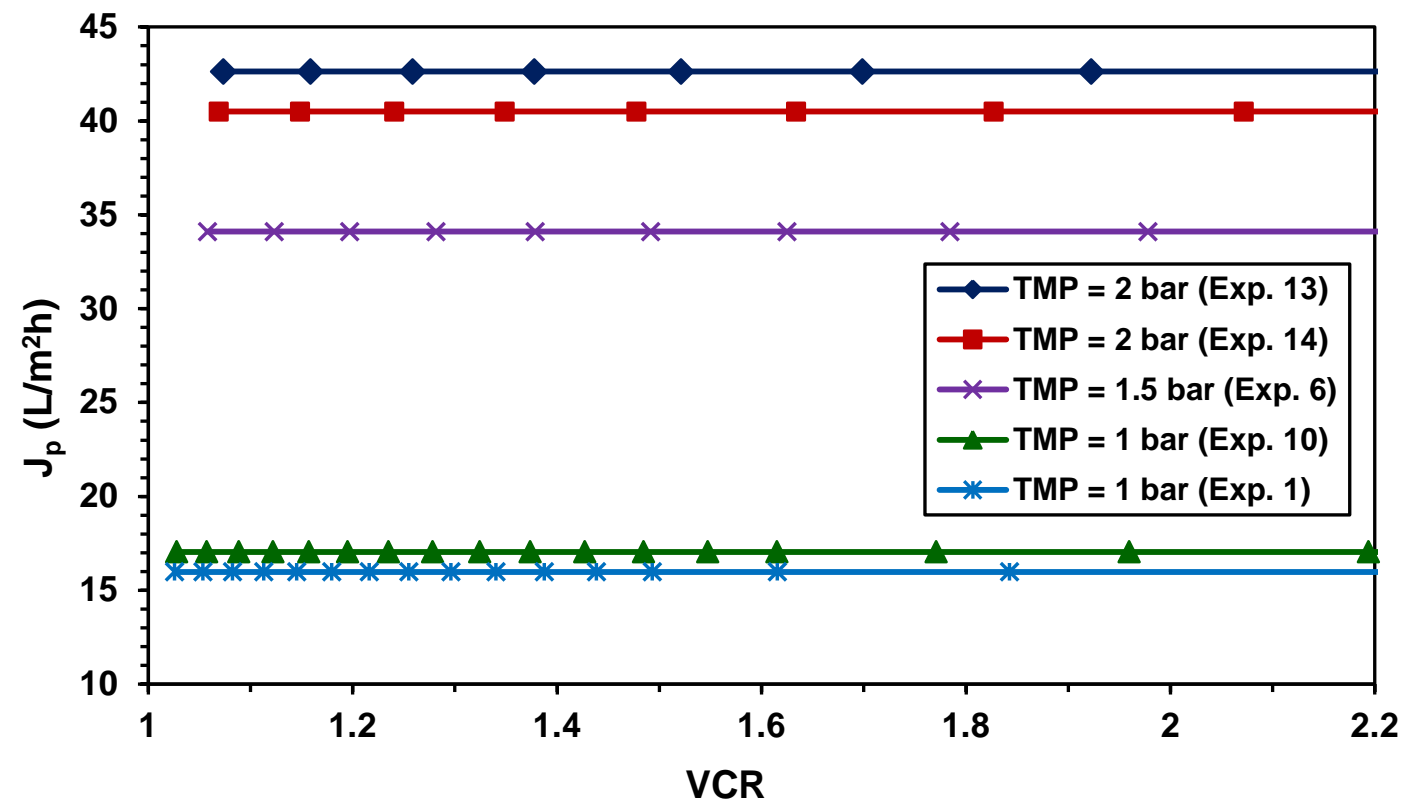

Figure 7. Experimental values of the permeate flux during the concentration process by ultrafiltration under different TMP using the $15 \mathrm{kDa}$ membrane. Symbols: experimental data. Lines: behavior trends. 
As it stated above, niosomes are broken at $\mathrm{pH}>12$ and large Span 80 aggregates and mixed micelles of Span 80 and SDS coexist in equilibrium with SDS monomers in the dispersion $\left(\mathrm{F}_{\mathrm{bis}}\right)$. During the UF process, retention of large aggregates and micelles take place by sieving effect of the UF membranes, as the pore size is assumed to be lower than the size of these structures. It has been documented that the mean pore radius of several 5 to $30 \mathrm{kDa}$ UF polymeric membranes was in the range from 0.8 to 11 $\mathrm{nm}$ [31], whereas the SDS micelle radius is about $2.5 \mathrm{~nm}$, with an average molecular weight of $14 \mathrm{kDa}[29,31]$. Furthermore, the excess of $\mathrm{Na}^{+}$cations drives micellar systems towards larger micelles [33-35] and also affect their shape [36]. However, besides sieving, other phenomena such as the effect of membrane charge, adsorption and concentration polarization, can affect the retention of surfactants.

Surfactants have tendency to adsorb at interfaces, so under UF conditions (dispersion F), part of SDS monomers can be adsorbed on the membrane surface and pore walls. Many researchers have demonstrated that for a strongly hydrophilic membrane as the ones used in this work, adsorption is unlikely unless the solute and the membrane have opposite charges [33,37]. However, in this case at $\mathrm{pH}>12$ the membrane negative charge is partially shielded by the excess of $\mathrm{Na}^{+}$ions and adsorption of SDS monomers could take place to some extent $[26,38]$. SDS monomers can also accumulate in the polarization layer under pressure conditions and form micelles although the SDS concentration in the bulk is lower than the CMC value. The mixed micelles are negatively charged and, although they are unlikely to be associated with the membrane, their presence in the polarization layer is admissible.

SDS monomers concentration has been measured throughout the experimental process, as indicated in Table 1. The fraction of SDS forming mixed micelles $\left(\operatorname{SDS}_{(\mathrm{mx})}\right)$, SDS monomers $\left(\operatorname{SDS}_{(\mathrm{m})}\right)$, and SDS adsorbed on the membrane and accumulated in the polarization layer $\left(\mathrm{SDS}_{(\mathrm{M}-\mathrm{PL})}\right)$, under UF conditions (dispersion $\left.\mathrm{F}\right)$, were calculated by the following mass balances, where identical fraction of mixed micelles in $F$ and $F_{\text {bis }}$ has been assumed:

$$
\begin{aligned}
& \operatorname{SDS}_{(\mathrm{mx})}=\frac{\mathrm{C}_{\mathrm{S}(\mathrm{Fd})} \mathrm{V}_{(\mathrm{Fd})}-\mathrm{C}_{\mathrm{S}(\mathrm{Fbis})} \mathrm{V}_{(\mathrm{Fbis})}}{\mathrm{C}_{\mathrm{S}(\mathrm{Fd})} \mathrm{V}_{(\mathrm{Fd})}} \\
& \mathrm{SDS}_{(\mathrm{m})}=\frac{\mathrm{C}_{\mathrm{S}(\mathrm{F})} \mathrm{V}_{(\mathrm{F})}}{\mathrm{C}_{\mathrm{S}_{(\mathrm{Fd})}} \mathrm{V}_{(\mathrm{Fd})}} \\
& \mathrm{SDS}_{(\mathrm{M}-\mathrm{PL})}=1-\mathrm{SDS}_{(\mathrm{mx})}-\mathrm{SDS}_{(\mathrm{m})}
\end{aligned}
$$

where $\mathrm{C}_{\mathrm{S}}$ is the SDS concentration and $\mathrm{V}$ is the volume of the dispersion, respectively.

Table 6 shows the distribution of the total SDS amount in the dispersion F. Under ultrafiltration conditions, most of the SDS is adsorbed on the membrane or accumulated in the polarization layer $\left(\mathrm{SDS}_{(\mathrm{M}-\mathrm{PL})}\right)$, being this fact the mainly responsible of the permeate flux decrease.

Being a process mainly controlled by convection, the increase of the driving force as TMP increases leads to the SDS monomers accumulated in the boundary layer to pass through the membrane whose charge is shielded by $\mathrm{Na}^{+}$ions. It should be taken into account that the excess of $\mathrm{Na}^{+}$ions cause micelles destabilization, resulting in a less compact micellar layer which facilitates permeation of the SDS monomers $[29,33,39]$. This fact is observed in Fig. $8 \mathrm{a}$, where the amount of SDS monomers, that 
freely pass through the membrane, increases as TMP increases, thereby decreasing the membrane rejection to SDS, as shown in Fig. 8b. These results show the existence of an antagonistic behavior between $J_{p}$ and $R_{s}$, to the extent that $R_{s}$ decreases as $J_{p}$ increases, as depicted in Fig. 9. A similar behavior of permeate flux increase, as well as surfactant concentration in permeates, with TMP can be found elsewhere $[29,32,40]$.

Table 6. Distribution of total SDS amount in dispersion F under ultrafiltration conditions: mixed micelles, $\operatorname{SDS}_{(\mathrm{mx})}$, free monomers, $\operatorname{SDS}_{(\mathrm{m})}$, and adsorbed on the membrane and accumulated in the polarization layer, $\mathrm{SDS}_{(\mathrm{M}-\mathrm{PL})}$.

\begin{tabular}{cccc}
\hline Experiment & $\begin{array}{c}\text { SDS }_{(\mathbf{m x})} \\
(\mathbf{w t .} \%)\end{array}$ & $\begin{array}{c}\mathbf{S D S}_{(\mathbf{m})} \\
(\mathbf{w t .} \%)\end{array}$ & $\begin{array}{c}\mathbf{S D S}_{(\mathbf{M}-\mathbf{P L})} \\
(\text { wt.\%) }\end{array}$ \\
\hline 1 & 38.40 & 8.64 & 52.96 \\
2 & 34.77 & 10.92 & 54.31 \\
3 & 37.31 & 8,64 & 54.05 \\
4 & 33.75 & 9.41 & 56.84 \\
5 & 37.49 & 9.12 & 53.39 \\
6 & 41.81 & 10.48 & 47.71 \\
7 & 35.08 & 9.40 & 55.53 \\
8 & 33.26 & 9.29 & 57.45 \\
9 & 33.87 & 10.67 & 55.46 \\
10 & 34.07 & 11.18 & 54.75 \\
11 & 35.62 & 8.47 & 55.91 \\
12 & 36.39 & 9.58 & 54.02 \\
13 & 36.53 & 11.12 & 52.35 \\
14 & 34.07 & 11.18 & 54.75 \\
15 & 35.19 & 10.74 & 54.07 \\
16 & 32.84 & 11.70 & 55.46 \\
17 & 33.75 & 9.41 & 56.84 \\
\hline
\end{tabular}

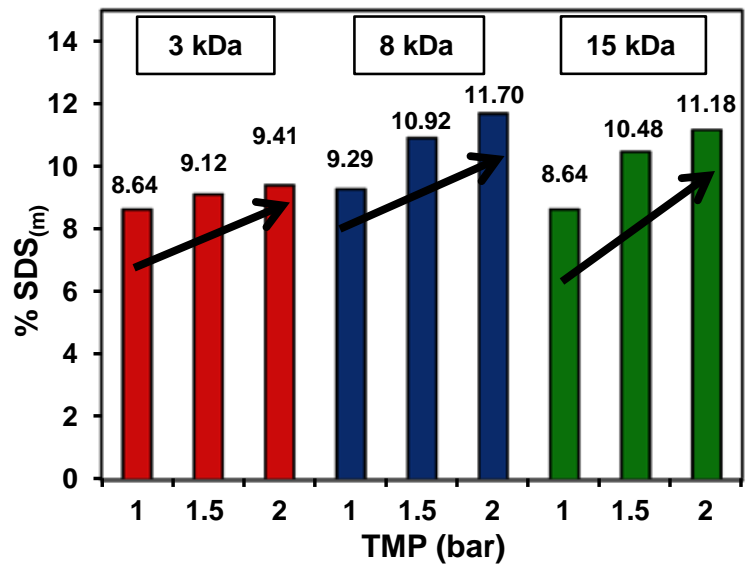

(a)

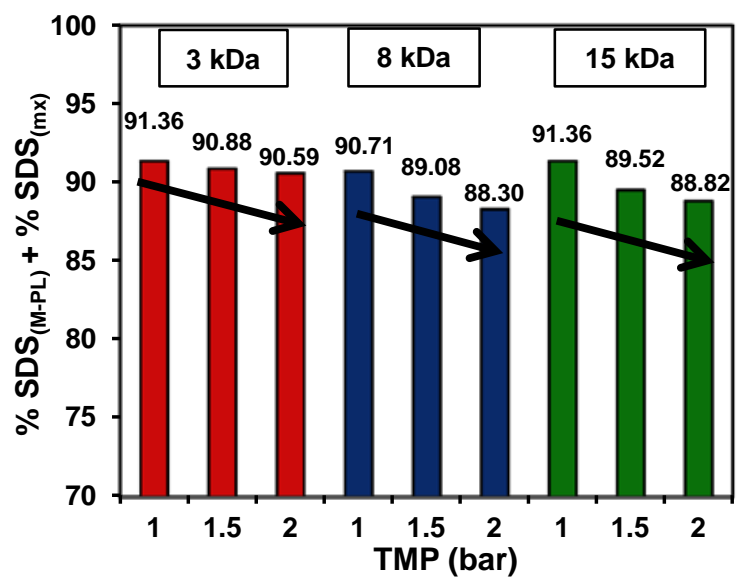

(b)

Figure 8. Variation of SDS amount (wt.\%) with TMP in the dispersion F: (a) SDS monomers, (b) SDS in mixed micelles plus adsorbed on the membrane and accumulated in the polarization layer. 


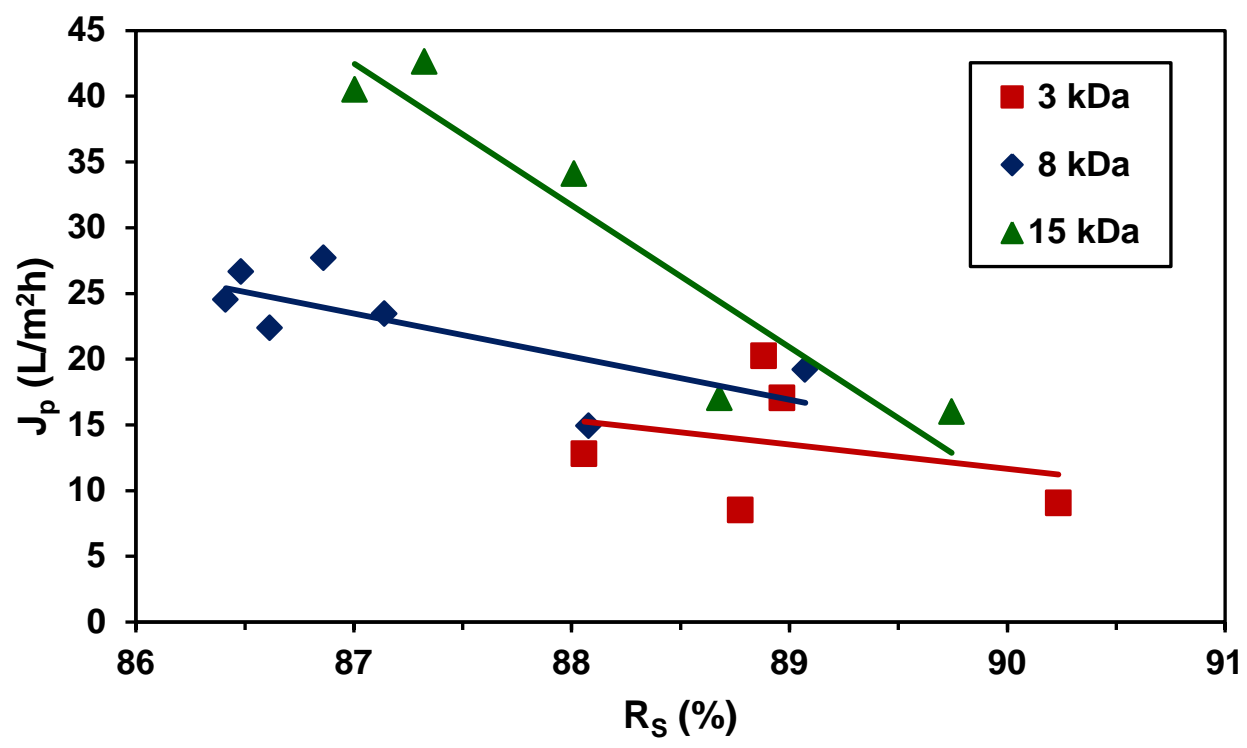

Figure 9. Relationships between the permeate flux and SDS rejection under ultrafiltration conditions. Symbols: experimental data. Lines: behavior trends.

The effects of TMP and $\mathrm{Na}^{+}$ions presence on $\mathrm{J}_{\mathrm{p}}$ have also been tested for single surfactant dispersions using the $15 \mathrm{kDa}$ membrane and the results have been compared with those of the surfactant mixtures. Fig. 10 shows that permeate flux increases with TMP for all systems but it also depends on the medium composition. The higher fluxes were obtained for Span $80\left(20 \mathrm{~mol} / \mathrm{m}^{3}\right)+$ SDS $\left(4 \mathrm{~mol} / \mathrm{m}^{3}\right)$ niosome dispersions at natural $\mathrm{pH}(\approx 7)$. For this system both niosomes and membrane have negative charge and electrostatic repulsions favor the solvent permeation. The lower flux observed for the dispersion with niosomes formulated only with Span 80 (20 $\mathrm{mol} / \mathrm{m}^{3}$ ) at $\mathrm{pH}>12$ can be attributed to accumulation of the negatively charged Span 80 large aggregates in the polarization layer, because of the membrane charge shielding by $\mathrm{Na}^{+}$ions. Zeta potential of Span 80 aggregates at $\mathrm{pH}>12$ was $-20 \mathrm{mV}$, probably due to the adsorption of hydroxyl ions; in addition, the presence of $\mathrm{Na}^{+}$ decreases the electrostatic repulsion between particles, which increases their tendency to accumulate in the polarization layer. A much lower $\mathrm{J}_{\mathrm{p}}$ was obtained for the system with formulation identical to the first one (Span $80+$ SDS) but at $\mathrm{pH}>12$, with $\mathrm{J}_{\mathrm{p}}$ values similar to those achieved for a single SDS dispersion at $\mathrm{pH}>12$, indicating that the presence of SDS monomers is the main cause of this permeate flux reduction. Comparison of the single SDS systems at $\mathrm{pH}>12$ and natural $\mathrm{pH}(\approx 6.9)$ shows a significant $\mathrm{J}_{\mathrm{p}}$ decrease in the former. This result confirms that the $\mathrm{Na}^{+}$ions shield the negatively charged membrane surface and also decrease the electrostatic repulsions between SDS monomers, yielding to their accumulation in the polarization layer. 


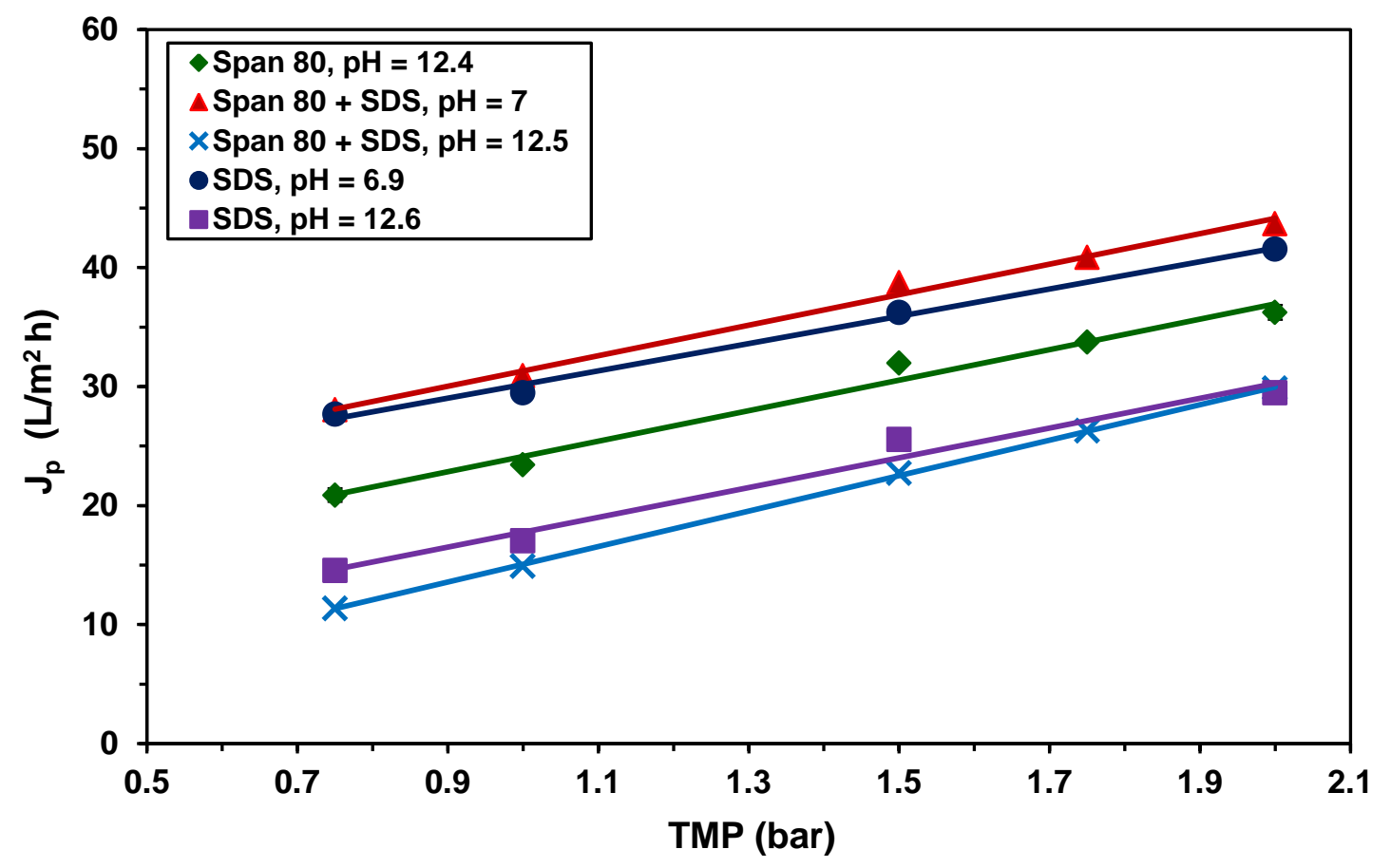

Figure 10. Relationships between the permeate flux and TMP for different medium compositions. Symbols: experimental data. Lines: behavior trends.

\section{Conclusions}

$\mathrm{ZrO}_{2}$ ceramic ultrafiltration membranes can be successfully used for the separation of ion lactate from the surfactants Span 80 and SDS in aqueous solutions at pH > 12 . Process optimization by RSM showed that, in the range of conditions studied (TMP: $1-$ 2 bar, NMWL: $3-15 \mathrm{kDa}$, and $\mathrm{C}_{\mathrm{A}}: 5-15 \mathrm{~mol} / \mathrm{m}^{3}$ ), best results were obtained for the 15 $\mathrm{kDa}$ membrane and a transmembrane pressure of 2 bar. Under these conditions the permeate flux $\left(J_{p}\right)$ was $42.63 \mathrm{~L} / \mathrm{m}^{2} \mathrm{~h}$ and SDS rejection $\left(R_{s}\right)$ was $87.3 \%$. Ion lactate concentration effect was not statistically significant on $\mathrm{J}_{\mathrm{p}}$ and its rejection was lower than $4.5 \%$. Span 80 rejection was $100 \%$ in all range of experimental conditions tested, as it forms large aggregates that are retained by membranes.

Although the differences between $R_{s}$ values were not statistically significant with 95\% significance level, an antagonistic behavior between $R_{s}$ and $J_{p}$ has been experimentally tested. It was observed that UF process was mainly controlled by convection and $\mathrm{J}_{\mathrm{p}}$ increased as TMP increases, being this effect more appreciable for membranes with higher NMWL. Besides, as $\mathrm{J}_{\mathrm{p}}$ increases part of SDS molecules adsorbed on the membrane or accumulated in the polarization layer pass through the membrane decreasing the SDS monomers rejection. The retention of surfactants at $\mathrm{pH}$ $>12$ are influenced by three predominant effects: the membrane sieving that yields retention of mixed micelles and large aggregates of Span 80 , the de-compaction of the polarization layer due to the micelles destabilization caused by the excess of $\mathrm{Na}^{+}$ions, and the shielding of the negatively charged membrane surface by $\mathrm{Na}^{+}$ions which improves the permeation of SDS monomers as $\mathrm{J}_{\mathrm{p}}$ increases.

This study complements a previously one performed with a $0.20 \mu \mathrm{m} \mathrm{TiO}_{2}$ microfiltration membrane and 0.3 bar TMP [15] where a significant permeate flux decline was obtained during the separation of components due to SDS monomers 
accumulated in the polarization layer and adsorbed within the large pores of the microfiltration membrane. A comparison between both studies shows that $\mathrm{J}_{\mathrm{p}}$ obtained with the $15 \mathrm{kDa}$ ultrafiltration membrane $\left(\mathrm{J}_{\mathrm{p}}=42.63 \mathrm{~L} / \mathrm{m}^{2} \mathrm{~h}\right.$ at TMP $=2$ bar $)$ was higher than the obtained with the $0.20 \mu \mathrm{m}$ microfiltration membrane $\left(J_{p}=19.19 \mathrm{~L} / \mathrm{m}^{2} \mathrm{~h}\right.$ at TMP $=0.3$ bar). Besides, smaller decrease of $J_{p}$ with relation to pure water flux $\left(J_{w}\right)$ was obtained with the UF membrane $\left(J_{p} / J_{w}=0.61\right)$ than with the microfiltration one $\left(J_{p} / J_{w}=\right.$ 0.38 ). These results indicate an improvement in the extraction-backextraction process of lactic acid with Span 80 and SDS niosomes using ultrafiltration membranes.

\section{Acknowledgments}

Financial support from the Ministerio de Economía y Competitividad (MINECO, Spain) through project CTQ2011-25239, and from Junta de Castilla y León through project BU055U16 cofinanced by the European Regional Development Fund (ERDFFEDER) is gratefully acknowledged. The authors would like to thank Dr. Carlos Álvarez (Scientific Technical Services, University of Oviedo, Spain) for his valuable help and assistance with TEM measurements.

\section{References}

[1] M.A. Abdel-Rahman, Y. Tashiro, K. Sonomoto, Lactic acid production from lignocellulose-derived sugars using lactic acid bacteria: overview and limits, $J$. Biotechnol. 156 (2011) 286-301.

[2] R. Datta, S.-P. Tsai, P. Bonsignore, S.-H. Moon, J.R. Frank, Technological and economic potential of poly(lactic acid) and lactic acid derivatives, FEMS Microbiol. Rev. 16 (1995) 221-231.

[3] K.M. Nampoothiri, N.R. Nair, R.P. John, An overview of the recent developments in polylactide (PLA) research, Bioresour. Technol. 101 (2010) 8493-8501.

[4] S. Taskila, H. Ojamo, The current status and future expectations in industrial production of lactic acid by lactic acid bacteria, in: J. Marcelino Kongo (Ed.), Lactic Acid Bacteria - R\& D for Food, Health and Livestock Purposes. InTech, 2013. doi: http://dx.doi.org/10.5772/51282.

[5] K.L. Wasewar, A.A. Yawalkar, J.A. Moulijn, V.G. Pangarkar, Fermentation of glucose to lactic acid coupled with reactive extraction: a review, Ind. Eng. Chem. Res. 43 (2004) 5969-5982.

[6] D. Yankov, J. Molinier, J. Albet, G. Malmary, G. Kyuchoukov, Lactic acid extraction from aqueous solutions with tri-n-octylamine dissolved in decanol and dodecane, Biochem. Eng. J. 21 (2004) 63-71.

[7] P. Pal, J. Sikder, S. Roy, L. Giorno, Process intensification in lactic acid production: a review of membrane based processes, Chem. Eng. Process. 48 (2009) 1549-1559.

[8] H. Huang, S.T. Yang, D.E. Ramey, A hollow-fiber membrane extraction process for recovery and separation of lactic acid from aqueous solution, Appl. Biochem. Biotechnol. 114 (2004) 671-688.

[9] R.-S. Juang, J.-D. Chen, H.-C. Huan, Dispersion-free membrane extraction: case studies of metal ion and organic acid extraction, J. Membr. Sci. 165 (2000) 5973.

[10] M. Rodríguez, M.J. González-Muñoz, S. Luque, J.R. Álvarez, J. Coca, Extractive ultrafiltration for the removal of carboxylic acids, J. Membr. Sci. 274 (2006) 209218.

[11] R.M. Geanta, M.O. Ruiz, I. Escudero, Micellar-enhanced ultrafiltration for the recovery of lactic acid and citric acid from beet molasses with sodium dodecyl sulphate, J. Membr. Sci. 430 (2013) 11-23. 
[12] J. Landaburu-Aguirre, E. Pongrácz, R.L. Keiski, Separation of cadmium and copper from phosphorous rich synthetic waters by micellar-enhanced ultrafiltration, Sep. Purif. Technol. 81 (2011) 41-48.

[13] J. Landaburu-Aguirre, E. Pongrácz, A. Sarpola, R.L. Keiski, Simultaneous removal of heavy metals from phosphorous rich real wastewaters by micellarenhanced ultrafiltration, Sep. Purif. Technol. 88 (2012) 130-137.

[14] M.O. Ruiz, J.M. Benito, B. Barriuso, J.L. Cabezas, I. Escudero, Equilibrium distribution model of betaine between surfactant micelles and water: application to a micellar-enhanced ultrafiltration process, Ind. Eng. Chem. Res. 49 (2010) 6578-6586.

[15] L. Roque, I. Escudero, J.M. Benito, Lactic acid recovery by microfiltration using niosomes as extraction agents, Sep. Purif. Technol. 151 (2015) 1-13.

[16] E. Acosta, Bioavailability of nanoparticles in nutrient and nutraceutical delivery, Curr. Op. Colloid Interface Sci. 14 (2009) 3-15.

[17] Y.-M. Hao, K. Li, Entrapment and release difference resulting from hydrogen bonding interactions in niosome, Int. J. Pharm. 403 (2011) 245-253.

[18] C. Marianecci, L. Di Marzio, F. Rinaldi, C. Celia, D. Paolino, F. Alhaique, S. Esposito, M. Carafa, Niosomes from 80s to present: the state of the art, Adv. Colloid Interface Sci. 205 (2014) 187-206.

[19] D.J. McClements, E.A. Decker, Y. Park, J. Weiss, Structural design principles for delivery of bioactive components in nutraceuticals and functional foods, Crit. Rev. Food Sci. Nutr. 49 (2009) 577-606.

[20] A.Y. Waddad, S. Abbad, F. Yu, W.L.L. Munyendo, J. Wang, H. Lv, J. Zhou, Formulation, characterization and pharmacokinetics of Morin hydrate niosomes prepared with various non-ionic surfactants, Int. J. Pharm. 456 (2013) 446-458.

[21] R. Fraile, R.M. Geanta, I. Escudero, J.M. Benito, M.O. Ruiz, Formulation of Span 80 niosomes modified with SDS for lactic acid entrapment, Desalin. Water Treat. 56 (2015) 3463-3475.

[22] L. Alonso, L. Roque, I. Escudero, J.M. Benito, M.T. Sanz, S. Beltrán, Solubilization of Span 80 niosomes by sodium dodecyl sulfate, ACS Sustainable Chem. Eng. 4 (2016), 1862-1869.

[23] B.A. Uzoukwu, L.M.L. Nollet, Analysis of surfactants, in: L.M.L. Nollet (Ed.), Handbook of Water Analysis, Marcel Dekker, New York., 2000, pp. 767-784.

[24] M. Kaszuba, J. Corbett, F.M. Watson, A. Jones, High-concentration zeta potential measurements using light-scattering techniques, Philos. Trans. R. Soc. A-Math. Phys. Eng. Sci. 368 (2010) 4439-4451.

[25] J. Wei, Q. Xue, Effects of surfactants on the tribological properties of a $\mathrm{Cr}_{2} \mathrm{O}_{3}$ coating, Wear 162-164 (1993) 229-233.

[26] E. Samper, M. Rodríguez, M.A. De la Rubia, D. Prats, Removal of metal ions at low concentration by micellar-enhanced ultrafiltration (MEUF) using sodium dodecyl sulfate (SDS) and linear alkylbenzene sulfonate (LAS), Sep. Purif. Technol. 65 (2009) 337-342.

[27] K. Xu, G.-M. Zeng, J.-H. Huang, J.-Y. Wu, Y.-Y. Fang, G. Huang, J. Li, B. Xi, H. Liu, Removal of $\mathrm{Cd}^{2+}$ from synthetic wastewater using micellar-enhanced ultrafiltration with hollow fiber membrane, Colloid Surf. A-Physicochem, Eng. Aspects 294 (2007) 140-146.

[28] J.-S. Yang, K. Baek, J.-W. Yang, Crossflow ultrafiltration of surfactant solutions, Desalination 184 (2005) 385-394.

[29] I. Kowalska, M. Kabsch-Korbutowicz, K. Majewska-Nowak, T. Winnicki, Separation of anionic surfactants on ultrafiltration membranes, Desalination 162 (2004) 33-40.

[30] A. Patist, P.D.T. Huibers, B. Deneka, D.O. Shah, Effect of tetraalkylammonium chlorides on foaming properties of sodium dodecyl sulfate solutions, Langmuir 14 (1998) 4471-4474. 
[31] K. Majewska-Nowak, I. Kowalska, M. Kabsch-Korbutowicz, Ultrafiltration of SDS solutions using polymeric membranes, Desalination 184 (2005) 415-422.

[32] E. Fernández, J.M. Benito, C. Pazos, J. Coca, Ceramic membrane ultrafiltration of anionic and nonionic surfactant solutions, J. Membr. Sci. 246 (2005) 1-6.

[33] L. Suárez, M.A. Diez, F.A. Riera, Transport mechanisms of detergent ingredients through ultrafiltration membranes, Sep. Purif. Technol. 136 (2014) 115-122.

[34] F.H. Quina, P.M. Nassar, J.B.S. Bonilha, B.L. Bales, Growth of sodium dodecyl sulfate micelles with detergent concentration, J. Phys. Chem. 99 (1995) 1702817031.

[35] M. Sammalkorpi, M. Karttunen, M. Haataja, Ionic surfactant aggregates in saline solutions: sodium dodecyl sulfate (SDS) in the presence of excess sodium chloride $(\mathrm{NaCl})$ or calcium chloride $\left(\mathrm{CaCl}_{2}\right)$, J. Phys. Chem. B 113 (2009) 58635870.

[36] C.S. Gangabadage, A. Najda, D. Bogdan, S.S. Wijmenga, M. Tessari, Dependence of the size of a protein-SDS complex on detergent and $\mathrm{Na}^{+}$ concentrations, J. Phys. Chem. B. 112 (2008) 4242-4245.

[37] A.-S. Jönsson, B. Jönsson, The influence of nonionic and ionic surfactants on hydrophobic and hydrophilic ultrafiltration membranes, J. Membr. Sci. 56 (1991) 49-76.

[38] L. Villafaña-López, M. Ávila-Rodríguez, M.P. González-Muñoz, Study of the zeta potential and streaming current of ultrafiltration membranes in contact with an anionic surfactant, Desalin. Water Treat. 56 (2015), 3456-3462.

[39] I. Kowalska, Surfactant removal from water solutions by means of ultrafiltration and ion-exchange, Desalination 221 (2008) 351-357.

[40] I. Kowalska, K. Majewska-Nowak, M. Kabsch-Korbutowicz, Influence of temperature on anionic surface active agent removal from water solution by ultrafiltration, Desalination 198 (2006) 124-131. 